\title{
Predicting Acute Urinary Retention in Patients with Elevated Post-Void Residuals
}

\author{
David B. Cahn ${ }^{\mathrm{a}} \quad$ Curtis P. Ross ${ }^{\mathrm{a}} \quad$ Elliot P. Dubowitch ${ }^{\mathrm{b}}$ \\ Michelle L. Persun ${ }^{\mathrm{a}} \quad$ Philip C. Ginsberga ${ }^{\mathrm{a}}$ Richard C. Harkaway ${ }^{\mathrm{a}}$

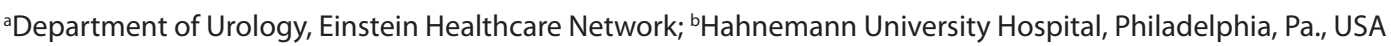

\section{Key Words}

Acute urinary retention $\cdot$ Benign prostatic hyperplasia . Elevated prostate volume $\cdot$ Elevated post void residual • Predicting acute urinary retention

\begin{abstract}
Objectives: To perform a retrospective analysis evaluating factors that may predict which men with elevated post-void residuals (PVRs) that were at increased risk to develop acute urinary retention (AUR). Methods: We retrospectively analyzed the records of 44 male patients who had 2 consecutive PVRs greater than $100 \mathrm{ml}$ over a 6-month period. Using regression analysis, we evaluated patient's age, PVR volume, prostate specific antigen (PSA) and transrectal ultrasound prostate volume with respect to development of AUR over 24 months. Results: Of the 44 patients, 4 developed AUR. When all factors were considered, prostate volume was determined to be the only that was statistically significant ( $p$ $=0.003)$. A 1-SD increase in prostate volume $(12 \mathrm{ml})$ led to a $19.6 \%$ increased risk of developing AUR. There was a strong correlation between PSA and prostate volume (0.787). A regression analysis was then repeated excluding prostate volume. PSA then became a statistically significant predictor of AUR $(p=0.007)$. A 1-SD increase in PSA $(1.377 \mathrm{ng} / \mathrm{ml})$ increased the patients' risk of developing AUR by $12.3 \%$. Conclusion: In men with an elevated PVR, increased transrectal ultrasound prostate volume or PSA may help predict which patients have an elevated risk of developing AUR within the next 24 months. This information may influence which patients need early surgical intervention versus medical therapy.

Copyright @ 2014 S. Karger AG, Basel
\end{abstract}

\section{KARGER}

Fax +4161306 1234

E-Mail karger@karger.ch

www.karger.com
(C) 2014 S. Karger AG, Basel

1015-9770/14/0082-0079\$38.00/0

Accessible online at:

www.karger.com/cur

\section{Introduction}

Acute urinary retention (AUR) is a medical emergency characterized by a sudden inability to void, often producing intense suprapubic pain. The diagnosis is typically made by performing a careful history and physical examination along with an ultrasound bladder scan after the patient attempts urination. An increased volume of urine in the bladder confirms the diagnosis. AUR may have many causes, the most common of which is benign prostatic hyperplasia (BPH). In a case study by Murray et al. [1], 53\% of AUR was caused by BPH, 7\% was caused by constipation, $7 \%$ by prostate cancer, and $5 \%$ was postoperative [1]. Other causes of AUR described by Murray included urethral strictures, neurologic disorders, medications/drugs, urinary tract infections and urolithiasis. Complications of urinary retention include kidney or bladder damage and urinary tract infections [2].

As mentioned previously, AUR most often results from $\mathrm{BPH}$, which is a common disease in aging men with a multifactorial etiology. However, it is most accepted that the pathophysiology of BPH includes increases in the amount of transitional zone prostate stroma and an increase in alpha 1a receptors [3]. These receptors are G protein coupled receptors that, when stimulated, result in smooth muscle contraction. In BPH, the adenomatous transitional zone that surrounds the urethra compresses it, causing bladder outlet obstruction. Increased detrusor voiding pressures develop in an attempt to bypass the obstruction. An in-depth history may even suggest that the patient strains to start his stream or possibly a Crede maneuver. Cystoscopic examination of the bladder may 
Table 1. Descriptive statistics of the subjects' age, PVR, PSA, and prostate volume in the overall, retention, and non-retention groups

\begin{tabular}{lccll}
\hline & Age & PVR & PSA & $\begin{array}{l}\text { Prostate } \\
\text { volume }\end{array}$ \\
\hline Overall $(\mathrm{n}=44)$ & & & & \\
$\quad$ Mean & 57.95 & 176.86 & 1.65 & 36.11 \\
$\quad$ Standard Deviation & 6.66 & 56.24 & 1.38 & 11.99 \\
$\quad$ Min & 45 & 100 & 0.4 & 20 \\
$\quad$ Max & 71 & 295 & 6.2 & 72 \\
Retention Group (n=4) & & & & \\
$\quad$ Mean & 58.50 & 145.00 & 3.55 & 58.50 \\
$\quad$ Standard Deviation & 8.39 & 33.93 & 1.79 & 10.25 \\
Min & 50 & 122 & 2.0 & 48 \\
$\quad$ Max & 70 & 195 & 6.1 & 72 \\
Non-Retention Group (n= 40) & & & & \\
$\quad$ Mean & 57.90 & 180.05 & 1.46 & 33.88 \\
$\quad$ Standard Deviation & 6.59 & 57.32 & 1.20 & 9.69 \\
Min & 45 & 100 & 0.4 & 20 \\
$\quad$ Max & 71 & 295 & 6.2 & 56 \\
\hline
\end{tabular}

reveal wall thickening, trabeculation, diverticula or even calculi. Hanno et al. [3] found that histologic evidence of $\mathrm{BPH}$ is found in approximately $65 \%$ of men ages 60 to 70 and $80 \%$ of men ages 70 to 80 .

BPH can be managed both pharmacologically and surgically. Medications may improve both lower urinary tract symptoms and urine flow. These include alpha-blockers, which antagonize the alpha receptors described above, or 5-alpha reductase inhibitors, which inhibit the conversion of testosterone to dihydrotestosterone. While the onset of action of the former may be several hours to days, the latter may take up to 6 months or more for patients to experience subjective symptom improvement. Although there is a delay in patient benefit, there have been studies showing that 5-alpha reductase inhibitors decrease the risk of AUR by $50-60 \%$ in men with enlarged prostates (over 30-40 ml) [3]. Surgical procedures such as transurethral microwave ablation of the prostate, transurethral resection of the prostate, transurethral electrode vaporization of the prostate and transurethral laser vaporization of the prostate will help remove the prostate tissue in the transitional zone to increase the diameter of the prostatic urethra for improved urine flow and subsequent decreased urine stasis. This is an application of Poiseuille's law, where flow is directly proportional to the radius to the fourth power.

Although AUR may be precipitated by surgery, anesthesia, infection or medications, de novo AUR remains a relatively unpredictable event in men with BPH. Hanno at al. [3] demonstrated no correlation between LUTS and degree of BPH. Furthermore, urinary retention caused by
Table 2. Descriptive statistics comparing variables between the retention and non-retention groups ( $\mathrm{p}<0.05$ is considered statistically significant)

\begin{tabular}{lllll}
\hline & Age & PVR & PSA & $\begin{array}{l}\text { Prostate } \\
\text { volume }\end{array}$ \\
\hline T test & 0.1699 & 1.1941 & 3.1848 & 4.8256 \\
P value & 0.8659 & 0.2391 & 0.0027 & $<.0001$ \\
\hline
\end{tabular}

$\mathrm{BPH}$ represents a significant indication for surgical treatment. It stands to reason that if physicians could predict which BPH patients would develop AUR, protocols could be modified to tailor treatment towards more aggressive interventions when indicated. In our investigation, we attempt to determine if post-void residual (PVR) volume predicts the likelihood of BPH patients developing AUR.

\section{Methods}

In this study, we retrospectively analyzed the records of 44 male patients seen at Albert Einstein Medical Center in Philadelphia, Pennsylvania who had 2 consecutive PVR determinations greater than $100 \mathrm{ml}$ over a 6-month period. Patients were excluded from the study if they were diagnosed with diabetes, had a history of transurethral surgery, urethral stricture disease, prostate cancer, or were currently on anticholinergic medication. Inclusion criteria for the study were the following: males who had a diagnosis of BPH with 2 consecutive PVRs greater than $100 \mathrm{ml}$ over a 6-month period. Prior to performing the regression analysis, all of the data was standardized. Then using regression analysis, we evaluated patient's age (mean age 58 years), PVR (mean PVR $177 \mathrm{ml}$ ), prostate specific antigen (PSA) (mean PSA $1.65 \mathrm{ng} / \mathrm{ml}$ ) and transrectal ultrasound (TRUS) prostate volume (mean TRUS volume $36 \mathrm{ml}$ ) with respect to the development of AUR over a 24-month period. As mentioned previously, AUR was defined by an inability for the patient to void urine.

\section{Results}

Out of the 44 patients analyzed, 4 patients $(9.1 \%)$ went on to develop AUR. All subjects had a range of ages of 45-71 years old. Average overall age was approximately 58 years with a SD of 6.66. The descriptive statistics of the subjects both overall and in the retention and non-retention groups may be seen below in table 1 . The difference between the mean prostate volume and PSA in the retention and non-retention groups is clearly demonstrated (table 2).

As demonstrated in table 3, when all four of our risk factors were considered, prostate volume was determined to be the only factor that was statistically signifi- 
Table 3. Regression analysis of age, PVR, PSA, and prostate volume in respect to developing urinary retention within a 24 month period

\begin{tabular}{lllll}
\hline $\begin{array}{l}\text { Standardized } \\
\text { variable }\end{array}$ & Coefficient & $\begin{array}{l}\text { Standard } \\
\text { error }\end{array}$ & p-value & $\begin{array}{l}95 \% \text { confidence } \\
\text { interval }\end{array}$ \\
\hline Age & -0.0259589 & 0.039799 & 0.518 & $-0.10646-0.0545422$ \\
PVR & -0.024207 & 0.041102 & 0.559 & $-0.1073436-0.0589297$ \\
PSA & -0.0299419 & 0.0611952 & 0.627 & $-0.1537209-0.0938371$ \\
Prostate volume & 0.195758 & 0.0604529 & 0.003 & $0.0728983-0.3174533$
\end{tabular}

Table 4. Correlation, R2, between age, PVR, PSA, and prostate volume

\begin{tabular}{lllll}
\hline & Age & PVR & PSA & $\begin{array}{l}\text { Prostate } \\
\text { volume }\end{array}$ \\
\hline Age & 1 & & & \\
PVR & -0.03495 & 1 & & \\
PSA & 0.088 & -0.2872 & 1 & \\
Prostate volume & 0.1422 & -0.2365 & 0.7871 & 1 \\
\hline
\end{tabular}

cant $(p=0.003)$ with respect to developing urinary retention. In addition, the coefficient for prostate volume was 0.195758 , meaning a 1 -SD increase in prostate volume $(12 \mathrm{ml})$ led to approximately a $19.6 \%$ increase risk of going into AUR over the next 24 months.

As displayed below in table 4 , it was also noted that there was a strong correlation between PSA and prostate volume (0.7871). A regression analysis was then repeated using age, PVR and PSA (excluding prostate volume in the analysis). As seen in table 5, PSA then became a statistically significant predictor of AUR $(p=0.007)$. PSA had a coefficient of 0.1232405 , meaning a 1-SD increase in PSA $(1.377 \mathrm{ng} / \mathrm{ml})$ increased the patients' risk of going into urinary retention by approximately $12.3 \%$.

The regression analysis was then repeated for a third time only with age, PVR and prostate volume (excluding PSA in the analysis). Here, the statistical significance of prostate volume became even stronger $(p<0.001)$. Comparing the $\mathrm{R}^{2}$ values for the regression analysis for PSA without prostate volume $\left(\mathrm{R}^{2}=0.1992\right)$ against the regression analysis for prostate volume without PSA $\left(\mathrm{R}^{2}\right.$ $=0.3642$ ) showed that prostate volume determined more of the variance than PSA of patients developing AUR.

\section{Discussion}

While elevated PVR alone does not predict eventual AUR, measurement of increased PVR associated with an increased prostate volume may help predict which patients will develop AUR within the next 24 months. An
Table 5. Regression analysis of standardized variables when examining age, PSA, and PVR and excluding prostate volume

\begin{tabular}{lrlll}
\hline $\begin{array}{l}\text { Standardized } \\
\text { variable }\end{array}$ & Coefficient & $\begin{array}{l}\text { Standard } \\
\text { error }\end{array}$ & p-value & $\begin{array}{l}95 \% \text { confidence } \\
\text { interval }\end{array}$ \\
\hline Age & -0.0105653 & 0.0439208 & 0.811 & $-.0993326-.078202$ \\
PVR & -0.0209999 & 0.0456745 & 0.648 & $-.1133114-.0713116$ \\
PSA & 0.1232405 & 0.0429608 & 0.007 & $.0364134-.2100676$ \\
\hline
\end{tabular}

increase of prostate volume by $1 \mathrm{SD}(12 \mathrm{ml})$ was associated with almost a $20 \%$ increased risk of going into AUR in men in this study. While this study is small, the inherent value in this fact cannot be understated: prostate size has a direct and significant correlation with developing urinary retention. Urologists may use a patient's TRUS prostate volume to predict if he has an increased risk of developing AUR.

As men age, their prostates naturally grow in size due to the effects of testosterone and dihydrotestosterone. Hanno et al. [3] have noted the correlation between age and the development of BPH. Correlating this data with our own, one may then infer that as men age, the rates of urinary retention increase due to the increasing frequency of BPH from the growth of adenomatous prostatic tissue. We believe that age was not a statistically significant predictor of developing AUR in this study because we were comparing different subjects at a range of ages. We hypothesize that if one compared the same man with advancing age, the risk of retention would be multiplied due to the inherent increase in size of the prostate as a result of naturally secreted hormones throughout the patient's lifespan.

In situations where TRUS prostate volume is not available, PSA may be used to predict AUR. In our study, PSA demonstrates a statistically significant correlation with developing AUR. In this case, a PSA increase of 1 -SD $(1.377 \mathrm{ng} / \mathrm{ml})$ is associated with an approximate $12 \%$ increase of developing AUR. In addition, the strong correlation between these 2 variables may allow PSA to act as a proxy for prostate volume. Other studies have noted this fact as well. Hanno et al. [3] state that PSA may be a surrogate for prostate volume as a predictor of AUR only in the absence of prostate cancer. Although there is current controversy over the use of PSA as a predictor of prostate cancer, in these circumstances, we can use it to monitor the prognosis of severity of the patient's BPH and response to treatment [3]. With this data, greater PSA may indicate a greater risk for AUR and worsening BPH. Several other studies have investigated 
the same variables as risk factors for AUR. In a pooled analysis of several large clinical trials, Roehrborn et al. $[4,5]$ demonstrated that prostate volume and PSA are strong predictors for AUR. In a separate analysis, Roehrborn et al. [6] showed that PSA is a strong predictor of prostate volume. Both of these findings are consistent with our study.

Other studies have investigated additional predictors for AUR. Using TRUS Doppler imaging, Shinbo et al. [7] demonstrated that transition volume index and resistive index are also strong predictors of AUR. Transition volume index was calculated by dividing the transition zone volume by the total prostate volume. Resistive index was calculated using the Doppler, evaluating vascular flow and the resistance of prostatic artery. Mishra et al. [8] pointed out that intraprostatic inflammation in men with BPH is an independent risk factor for AUR, suggesting that anti-inflammatory medications may have a role in the treatment of symptomatic BPH and prevention of AUR. Emberton et al. [9] showed that patients not symptomatically responding to $10 \mathrm{mg}$ alfuzosin daily are at a significant risk for developing AUR. Although these factors were not analyzed in our own study, one must acknowledge that AUR has a significant multifactoral etiology.

Our current study was unique in that all 44 men selected suffered from bladder outlet obstruction, with 2 consecutive PVRs within a 6-month period greater than $100 \mathrm{ml}$. Moreover, the average age of the patients was 58 years. Given this information, these 44 patients were prime subjects to study for possible development of AUR and thus it was surprising that only 4 developed AUR. At Massachusetts General Hospital, Meigs et al. [10] demonstrated a greater prevalence of AUR associated with both older age groups and higher international prostate symptom scores. Our results were consistent with other studies, finding that PSA and prostate volume are significant risk factors for AUR and at times may act as proxies for one another.

Although clinicians may not be able to prevent AUR completely, we may be able to help decrease its prevalence using the information from this study. For example, knowing the predictability of AUR associated with larger prostate volumes, a physician may want to more aggressively treat a patient that has a large prostate volume even if PVRs have consistently been measured around $100 \mathrm{ml}$. On the contrary, using the information from this study, more conservative treatment may be appropriate for a patient with a small prostate and PVRs twice as high as the first patient. Although this new information may be used as guidelines, we still recommend the physician make a clinical decision on a case-by-case basis. Additionally, the use of PSA may be a substitute for prostate volumes in predicting which patients will develop urinary retention. This may be especially helpful in evaluating inpatients, where blood draws are routine and TRUS may be costly and unnecessary in this setting, or for patients who are unable or unwilling to undergo transrectal ultrasonography.

We believe that a further study may wish to use a larger sample size to reexamine the association of TRUS prostate volume and urinary retention. Additionally, it would be interesting to repeat a regression analysis comparing the urine flow rates of these patients and its correlation to the development of AUR.

Even though this study has suggested predictors of AUR, it was not without limitations. This study had a relatively small sample size, with only 44 subjects and 4 going into AUR. Furthermore, this study is retrospective in nature, and the follow-up was relatively short at only 24 months. Patients' BPH medications were not taken into account in this retrospective study. Any prospective study design should include data on alpha-blockers and 5-alpha reductase inhibitors in order to be able to stratify results in this manner. Performing a larger study and developing a normogram which stratifies AUR risk for BPH patients will guide management decisions and help to prevent episodes of AUR, as well as the associated discomfort, emergency room visits, and health care costs.

\section{Conclusion}

In our study, measurement of elevated PVR along with an increased prostate volume was a statistically significant predictor of patients that will develop AUR within the next 24 months. In the absence of a TRUS prostate volume, PSA was an alternative to help the physician predict which patients will develop AUR. The information uncovered in this study may help influence which patients may need early surgical intervention versus medical therapy. In this population, the objective of the physician should be not only to manage patient the patient's symptoms but also to prevent the numerous sequelae of symptomatic BPH. 


\section{References}

1 Murray K, Massey A, Feneley RC: Acute urinary retention - a urodynamic assessment. $\mathrm{Br}$ J Urol 1984;56:468-473.

2 Tanagho EA, McAninch JW: Smith's General Urology, ed 17. New York, McGraw Hill Medical, 2008.

3 Hanno PM, Malkowicz SB, Wein AJ: Penn Clinical Manual of Urology. Philadelphia, Saunders, 2007.

4 Roehrborn CG, Malice M, Cook TJ, Girman CJ: Clinical predictors of spontaneous acute urinary retention in men with LUTS and clinical BPH: a comprehensive analysis of the pooled placebo groups of several large clinical trials. Urology 2001;58:210-216. $\checkmark 5$ Roehrborn CG, McConnell JD, Lieber M Kaplan S, Geller J, Malek GH, Castellanos R, Coffield S, Saltzman B, Resnick M, Cook TJ, Waldstreicher J: Serum prostate-specific antigen concentration is a powerful predictor of acute urinary retention and need for surgery in men with clinical benign prostatic hyperplasia. Urology 1999;53:473-480.

6 Roehrborn CG, Boyle P, Gould AL, Waldstreicher J: Serum prostate-specific antigen as a predictor of prostate volume in men with benign prostatic hyperplasia. Urology 1999; 53:581-589.

7 Shinbo H, Kurita Y, Takada S, Imanishi T, Otsuka A, Furuse H, Nakanishi T, Mugiya S, Ozono S: Resistive index as risk factor for acute urinary retention in patients with benign prostatic hyperplasia. Urology 2010;76: 1440-1445.
8 Mishra VC, Allen DJ, Nicolaou C, Sharif H, Hudd C, Karim OM, Motiwala HG, Laniado ME: Does intraprostatic inflammation have a role in the pathogenesis and progression of benign prostatic hyperplasia? BJU Int 2007; 100:327-331.

9 Emberton M, Lukacs B, Matzkin H, Alcaraz A, Elhilali M, Vallancien G: Response to daily $10 \mathrm{mg}$ alfuzosin predicts acute urinary retention and benign prostatic hyperplasia related surgery in men with lower urinary tract symptoms. J Urol 2006;176:1051-1056.

-10 Meigs JB, Barry MJ, Giovannucci E, Rimm EB, Stampfer MJ, Kawachi I: Incidence rates and risk factors for acute urinary retention: the health professionals followup study. J Urol 1999;162:376-382. 